\title{
Galling Resistance of An Anti-friction Coating on Oil-casing Couplings
}

\author{
Shilong ZHAO ${ }^{1, a,}$, Xuefeng $\mathrm{ZHANG}^{1, \mathrm{a}}$, Dingmen $\mathrm{YANG}^{2, \mathrm{a}}$, Xi WANG ${ }^{3, \mathrm{a}}$ and Zhao \\ $\mathrm{MENG}^{1, \mathrm{~b}}$ \\ ${ }^{1}$ College of Materials Science and Technology, Xi'an University of Science \& Technology, Xi'an \\ 710054 \\ ${ }^{2}$ CNPC Baoji Petroleum Steel Pipe Co., Ltd, Baoji 721008 \\ ${ }^{3}$ Baoji Zhujin Petroleum Steel Pipe Co., Ltd. Baoji 721006 \\ ashilong3611@163.com¹, bmoonshow1963@163.com
}

\begin{abstract}
Generally, oil tubing and casing connections made of carbon steel are connected using phosphate-treated coupling, but high-grade steel oil casing can only be connected using copperized couplings, which are expensive and result in environmental pollution. A new anti-friction coating was prepared by adding suitable amounts of nanoparticles into a highly pure and concentrated nano-copper suspension, with epoxy resin as a binder. Laboratory tests and full-scale make and break tests show that a heterogeneous copper layer is formed after curing when this coating was applied to the phosphate layer surface of couplings made of P110 and P110S casings. This can greatly reduce the make-up torque of casing thread, and can effectively improve or even eliminate galling of high-grade steel oil casing.
\end{abstract}

\section{Introduction}

Oil-casing pipes are widely used for drilling in oil wells; as many casing pipes and threaded couplings are used in such oil wells, the failure of even one casing pipe or coupling can result in huge economic losses. Galling, which often occurs during the screwing of threaded pipe couplings, is not only one of the most common forms of failure but also a technical problem that plagues oilfield users and manufacturers ${ }^{[1,2]}$. According to the newly defined IS0 13679 standard $^{[3]}$, galling is a form of wear caused by adhesion between sliding metal surfaces that are in mutual contact. Relative sliding between the metals leads to tear in the cold-welded parts. A heavy tear can lower the sealing and joint strength of the oil casing, thus leading to leak or accidents.

The main factors that cause thread galling can be divided into two broad categories, namely, the thread quality and the controlling of on-site operating parameters ${ }^{[4]}$. The fundamental cause of galling is excessive contact stress between the partial tooth surfaces during make and break owing to excess make-up torque and unfitable geometric constraints, and this excessive contract stress exceeds the yield strength of the threaded metal, resulting in deformation of the threaded plastic ${ }^{[5]}$. Dong $(2010)^{[6]}$ found that for the same thread

\footnotetext{
* Corresponding author:shilong3611@163.com
} 
parameters and operating environmental conditions, the effect of make-up torque on thread galling is very obvious, with a higher possibility of galling with increasing make-up torque. $\mathrm{Du}(2001)^{[7]}$ compared a number of surface treatments and studied the effect of the thickness of the phosphate layer on the anti-galling properties of different tubings; copperizing the coupling was found to be most effective in improving the galling resistance. However, copperized couplings cannot be widely used because of economic and environmental issues $^{[8]}$.

Therefore, it is necessary to develop a new anti-galling coating that exhibits good galling resistance. A new anti-galling coating was prepared using patented technology $y^{[9,10,11]}$ by adding a suitable amount of nano-particles in the highly concentrated nano-copper suspension, with epoxy resin as the main binder. Epoxy resins contain polar hydroxy and epoxy groups, which help to improve the invasive and adhesion force of entering into phosphate layer and have excellent bonding properties with the metal matrix ${ }^{[12]}$. Both nano-copper and nano-PTFE particles have good anti-wear and anti-friction properties; nano-copper particles, in particular, can be used in a heavy-load, low speed, and high temperature vibration environment ${ }^{[13,14]}$. This coating was named AFRICO (Anti-Friction Coating). AFRICO forms a thin nano-copper film after curing when it is applied on the surface of the phosphate layer of API (American Petroleum Institute) or non-API couplings; this coating shows excellent anti-friction effect during make-up and can effectively reduce friction and make-up torque between the threads to improve the anti-galling property of tubing and casing.

\section{Experimental}

Preparation of the AFRICO coating. First, a nano-copper suspension was prepared using patented technology ${ }^{[9]}$, and the $\mathrm{pH}$ of the suspension was adjusted to 7 by adding $\mathrm{NaOH}$ after centrifugal concentration for $5 \mathrm{~min}$ at $2000 \mathrm{rpm}$. Then, the nano-copper suspension was analyzed by dynamic light scattering and x-ray diffraction (XRD) to determine the particle size and purity. The nano-copper suspensions, nano-PTFE and nano- $\mathrm{TiO}_{2}$ particles, etc were mixed with a suitable amount of epoxy resin to prepare the AFRICO (defined as AF hereinafter) series in accordance with the patent technology ${ }^{[10]}$. Depending on the steel grade of the tubing and casing used, the AF series can be divided into four groups of different compositions, namely, AF-01, AF-02, AF-03, and AF-04. Among these samples, the dosage of the epoxy resin in AF-02 is half of that in AF-01, AF-03 and AF-04 contained added nano- $\mathrm{TiO}_{2}$ on the basis of the AF-01 and AF-02.

The test of friction coefficient of AF-01 layer. The anti-friction performance of AF-01 was tested in the laboratory, as the AF-01 was composed of the basic composition in the AF series. Two pieces of samples were selected for subsequent tests, where the two pieces of samples were treated with phosphate for 20 min at 95-98 degrees centigrade, with phosphating liquid of Mn series, and the thickness of the phosphate layer was about 32 36 $\mu \mathrm{m}$; the surface of one was coated with AF-01, and the other was used as the reference sample. The two samples were coated with compound grease before the test.

Scanning electron microscopy of grinding cracks in the AF-01 and reference samples. The grinding cracks of the AF-01 and reference samples under a maximum load of $10 \mathrm{~N}$ were detected by scanning electron microscopy (SEM).

Full-scale make-and-break tests for knuckle-thread casing of steel P110. Full-scale make and break tests were conducted in the production line of a BX petroleum steel pipe plant. Five groups of P110 $\Phi 139.7 \mathrm{~mm} \times 9.17 \mathrm{~mm}$ API casings were selected, and the couplings were treated with the above-mentioned high temperature phosphating process. The thread sizes were carefully checked to select casing and couplings of similar tolerance in the test. 
The surface of the four phosphate couplings was brushed twice with AF-01, AF-02, AF-03, and AF-04, respectively, and the interval between coatings was $24 \mathrm{~h}$ based on preliminary experiments. Then, according to the standard make-up program of the plant, compound grease was applied to the five casing pipes before the test. The make-up torques were compared against the reference sample to determine the improvement in galling resistance.

Full scale make and break tests for knuckle-thread casing of P110S steel. Compared with P110 steel, the contents of S, P and Mn in P110S steel are decreased, while those of $\mathrm{Cr}$ and Mo are increased, resulting in the improvement of sulfide stress cracking (SSC) resistance and a 10\% decrement in yield strength. Copperized couplings are normally used in P110S because of their high galling resistance. The chemical composition is shown in Table 1.

TABLE1 CHEMICAL COMPOSITION OF P110S (\%)

\begin{tabular}{cccccccccccccc}
\hline $\begin{array}{c}\text { Gra } \\
\text { de }\end{array}$ & $\mathrm{C}$ & $\mathrm{Si}$ & $\mathrm{M}$ & $\mathrm{S}$ & $\mathrm{P}$ & $\mathrm{Ni}$ & $\mathrm{Cr}$ & $\mathrm{M}$ & $\mathrm{Cu}$ & $\mathrm{V}$ & $\mathrm{Ti}$ & $\mathrm{Nb}$ & $\mathrm{B}$ \\
\hline $\mathrm{P} 11$ & 0. & 0. & 0. & 0.0 & 0.0 & 0. & 0. & 0. & 0. & 0. & 0. & 0.0 & 0.00 \\
$0 \mathrm{~S}$ & 27 & 25 & 40 & 03 & 08 & 03 & 96 & 83 & 05 & 10 & 03 & 03 & 03 \\
\hline
\end{tabular}

The full scale make and break tests were conducted in the production line of a JS petroleum steel pipe plant. Five groups of P110S $\Phi 139.7 \mathrm{~mm} \times 9.17 \mathrm{~mm}$ API casings were selected, and the couplings were treated with phosphate. The thread sizes were carefully checked to select for similar tolerance of casing and couplings before the make and break tests.

The surface of four sets of phosphate couplings were brushed twice with AF-01, and the interval between two coatings was $24 \mathrm{~h}$. Then, after $24 \mathrm{~h}$ of the AF coating, we conducted make and break tests according to the standard make-up program of the plant using specimens coated with compound grease.

\section{Results and Discussion}

The friction coefficients of AF-01 layers under different loads. The tribo-test was conducted with a $\mathrm{Si}_{3} \mathrm{~N}_{4}$ ball as the counter body and the loads used were $2 \mathrm{~N}, 5 \mathrm{~N}$, and $10 \mathrm{~N}$. The AF-01 friction coefficient curves under different loads were attained at a tribo-tester speed of $224 \mathrm{rpm}$ for $10 \mathrm{~min}$, as shown in Fig.1.

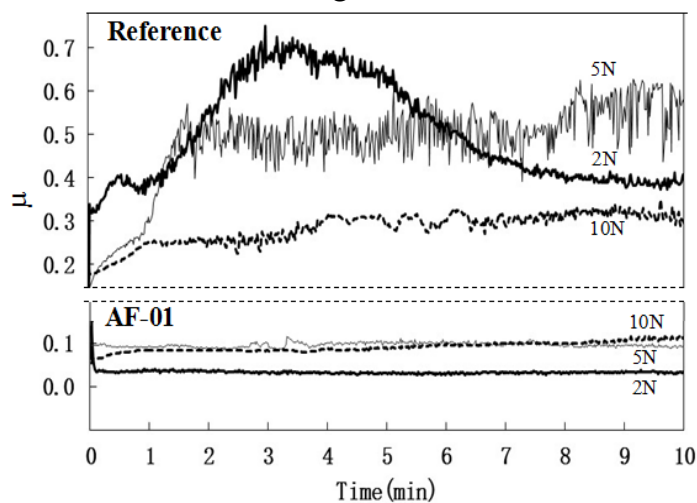

Fig.1 The curves of friction coefficient under different loads 
Fig. 1 shows the change in friction coefficient with time under different loads. In all cases, the friction coefficient of the reference sample is greater than that of the AF-01 sample. Moreover, the range of friction coefficients is larger for the reference sample, and reduces gradually with time. It can be seen that, compared to the reference sample, the friction coefficient for the AF-01 sample hardly changes on increasing the load from $2 \mathrm{~N}$ to $5 \mathrm{~N}$ and $10 \mathrm{~N}$. In particular, the friction coefficients for loads of $5 \mathrm{~N}$ and $10 \mathrm{~N}$ are nearly constant. Under loads of $2 \mathrm{~N}$ and $5 \mathrm{~N}$, the average friction coefficients of the AF-01 sample are reduced by $93.8 \%$ and $81.3 \%$, respectively compared with the reference. However, under a load of $10 \mathrm{~N}$, the average friction coefficients of the AF-01 and the reference samples are 0.093 and 0.292 , respectively, which indicate that the phosphate layer of the reference sample is not worn out.

The results of the tribo-test indicate that AF-01 layers can significantly reduce the friction coefficient of the phosphate sample.

SEM analysis of grinding cracks. The surface morphology of the grinding cracks under the maximum load of $10 \mathrm{~N}$ was studied by SEM. The SEM images of the grinding crack in the AF-01 and reference samples are shown in Fig.2 and Fig.3, respectively.

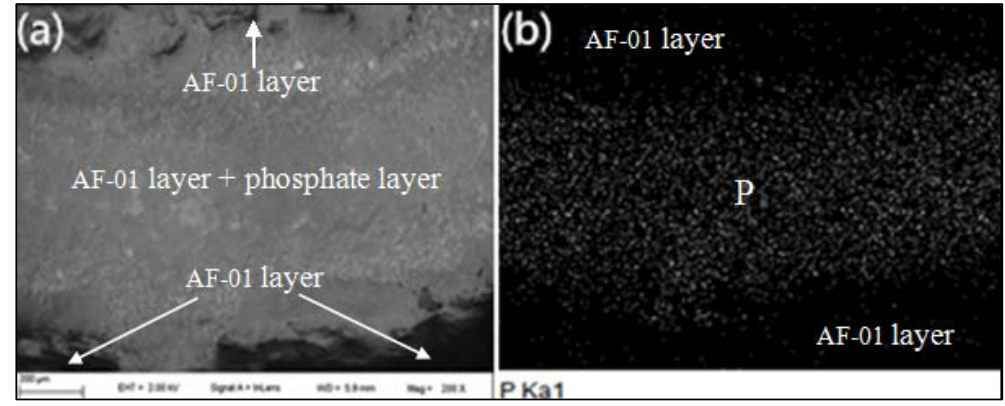

Fig.2 SEM and EDX images of the grinding crack in the AF-01 sample

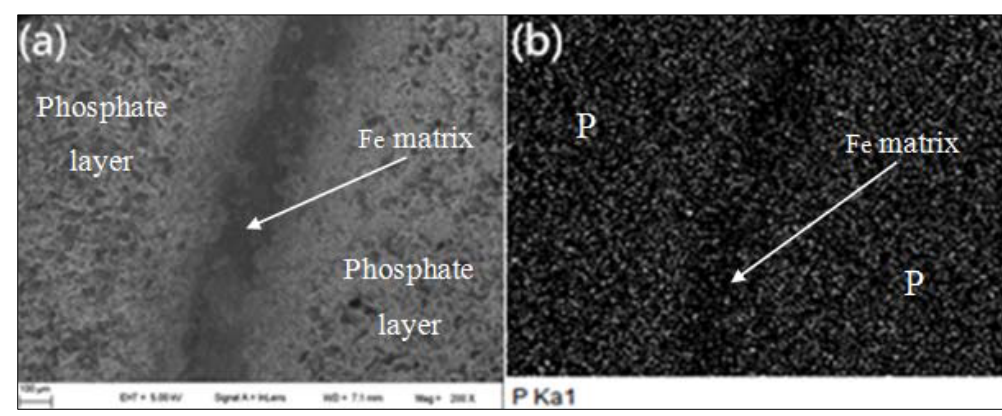

Fig.3 SEM and EDX images of the grinding crack in the reference sample

Figs.2 (a) and (b) show that the phosphate layer on the AF-01 sample is not worn out, unlike the phosphate layer in the reference sample, which is damaged and incomplete, as seen in Figs.3 (a) and (b). This observation can explain why the friction coefficient of the reference sample decreases with an increase in the load. Additionally, in the reference sample, the Fe matrix is in direct contact with the $\mathrm{Si}_{3} \mathrm{~N}_{4}$ ball, thus further decreasing the friction coefficient.

The small-sized nano-copper particles in AF-01 filled the pores in the phosphate layer to form a firm and soft anti-friction nano-copper layer with good ductility, which can greatly reduce the friction coefficient of the AF-01 specimen. 
Results of full-scale make and break tests for knuckle-thread casing of P110 steel. According to the standard GB/T 17745-1999 for P110 steel, the actual selection of optimal torque by the factory was $8700 \mathrm{~N} \cdot \mathrm{m}$ and the starting value of the torque for measurements was $1100 \mathrm{~N} \cdot \mathrm{m}$. The $\mathrm{J}$ value and torque-turns data of the five sets of casings are shown in Table 2.

TABLE.2 RESULTS OF THE MAKE-UP TEST

\begin{tabular}{cccccccc}
\hline Coating type & $\begin{array}{c}\mathrm{S} / \mathrm{m} \\
\mathrm{m}\end{array}$ & $\begin{array}{c}\mathrm{A} / \mathrm{m} \\
\mathrm{m}\end{array}$ & $\mathrm{J} / \mathrm{mm}$ & $\begin{array}{c}\mathrm{N} \\
\left.\max ^{\prime} / \mathrm{N} \cdot \mathrm{m}\right)\end{array}$ & $\alpha /$ turns & $\begin{array}{c}\mathrm{N}_{\mathrm{L}} / \mathrm{m} \\
\mathrm{m}\end{array}$ & Situation of galling \\
\hline Reference & 21.5 & 16.8 & 14.2 & 8502 & 1.4 & 204 & No galling \\
AF-01 & 21.4 & 16.9 & 12.7 & 8901 & 2.2 & 204 & No galling \\
AF-02 & 21.7 & 17.0 & 12.5 & 8661 & 2.6 & 204 & No galling \\
AF-03 & 21.7 & 16.9 & 12.5 & 8769 & 2.4 & 204 & No galling \\
AF-04 & 21.0 & 17.0 & 12.2 & 8769 & 2.8 & 204 & No galling \\
\hline
\end{tabular}

Note: S: stand-off of couplings A: stand-off of pipes

$\mathrm{N}_{\text {max }}$ : maximum torque $\quad \alpha$ : tightening laps

$\mathrm{N}_{\mathrm{L}}$ : length of couplings $\mathrm{J}$ : end of pipe to center of couplings

Fig.4 shows the torque-turns curve of make-up of the five casings.
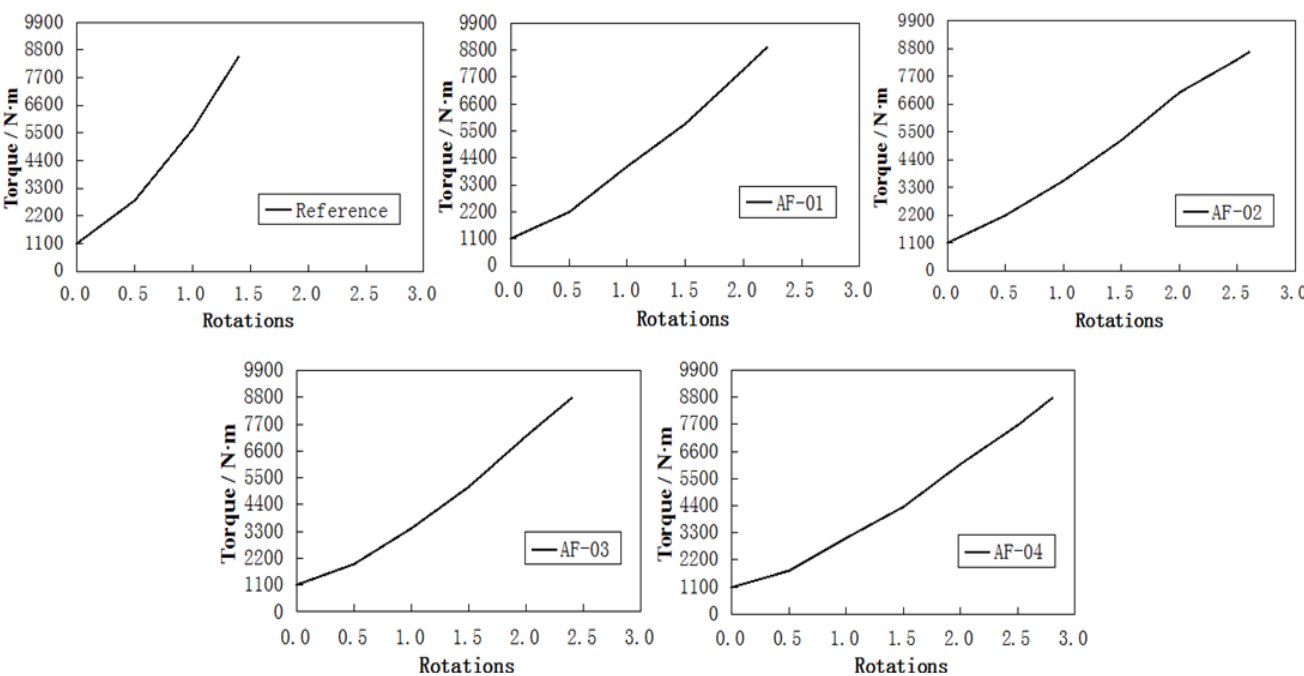

Fig.4 Make-up torque curves of the five casings

In order to clearly compare the test results of the five casings, the influence of the actual stand-off of couplings and pipes on the result of the experiment should be calculated, and the parameters of the reference casing (phosphate coupling with no AF) were used as a standard to adjust the $\mathrm{J}$ value ( the adjusted $\mathrm{J}$ value) of the other four casings. The correction formula of the adjusted $\mathrm{J}$ value of the AF- 01 casing is as follows:

$$
J_{\mathrm{a}}=J+\left(S_{0}-S\right)+\left(A-A_{0}\right)
$$


where

$J_{\mathrm{a}}=$ the adjusted $\mathrm{J}$ value of the AF-01 casing

$J \quad=\mathrm{J}$ value of the AF-01 casing;

$S=$ the stand-off of the coupling used for the AF-01 casing;

$S_{0} \quad=$ the stand-off of the coupling used for the reference;

$A \quad=$ the stand-off of the pipe used for the AF-01 casing;

$A_{0} \quad=$ the stand-off of the pipe used for the reference.

The pitch of the coupling (P) was $3.175 \mathrm{~mm}$, and the length of thread engagement (LE) $X_{0}$ of the AF-01 specimen when the make-up torque reached $1100 \mathrm{~N} \cdot \mathrm{m}$ could be obtained as follows:

$$
X_{0}=N_{\mathrm{L}} / 2-J_{\mathrm{a}}-\alpha * \mathrm{p}
$$

where

$N_{\mathrm{L}} \quad=$ the length of coupling used for the AF-01 casing;

$\alpha \quad=$ the total tightening turns of the AF-01 casing.

Therefore, the real-time LE $X_{\mathrm{i}}$ of AF-01 casing is given by:

$$
X_{\mathrm{i}}=X_{0}+\alpha_{\mathrm{i}} * \mathrm{P}
$$

where

$X_{\mathrm{i}} \quad=$ the real-time LE of the AF-01 casing ( $\left.\mathrm{i}=1,2,3,4,5,6,7\right)$.

The adjusted $\mathrm{J}$ values of the other three casings can be obtained by using the same method. The torque-LE curves of the five casings after adjusting the $\mathrm{J}$ value are shown in Fig.5.

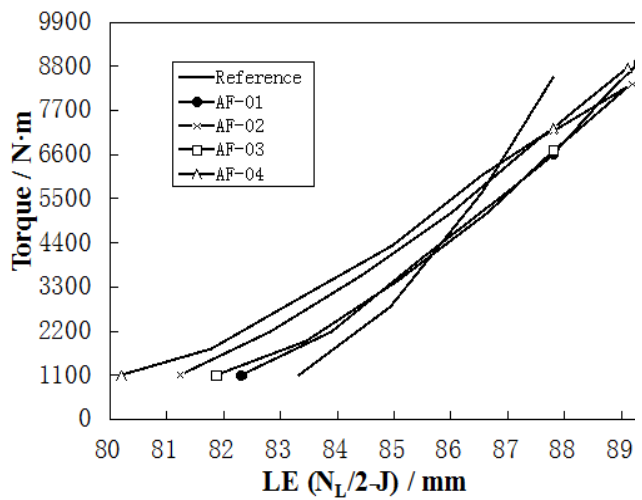

Fig.5 Make-up torque curves of the five casings after adjusting the $\mathrm{J}$ value

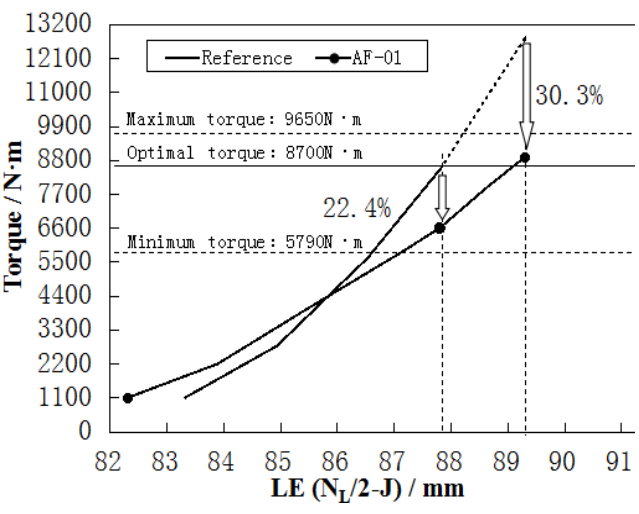

Fig.6 Make-up torque curves of AF-01-coated and reference casings

Fig. 5 shows that the engagement positions of the 4 AF casings (AF-01, AF-02, AF-03, and AF-04) at the starting torque of $1100 \mathrm{Nm}$ are $1.05 \mathrm{~mm}, 2.10 \mathrm{~mm}, 1.46 \mathrm{~mm}$, and 3.14 $\mathrm{mm}$ ahead of the reference, respectively. The LE values of the $4 \mathrm{AF}$ casings are $1.49 \mathrm{~mm}$, $1.71 \mathrm{~mm}, 1.71 \mathrm{~mm}$, and $1.30 \mathrm{~mm}$ longer than that of the reference, respectively. In other words, AF couplings can withstand much more drawing load than phosphate coupling under conditions of no galling.

Fig. 5 also shows that the slope of the curves of AF casings is smaller than that of the reference. The curve of each AF casing intersects the curve of the reference sample, which 
indicates the torque reversal point. The shorter the distance between the starting torque and the reversal point, the greater the decrement in make-up torque. The effect of the AF-01 layer was found to be the best by comprehensive comparison.

Fig. 6 shows the torque-LE curves of the reference and the AF-01 specimen based on the adjusted $\mathrm{J}$ value, which shows that the torque of the AF- 01 specimen is reduced by $22.4 \%$ at the same LE. At the same time, the torque of the AF- 01 specimen is reduced by $30.3 \%$ at the optimal torque of the reference specimen. Because the galling trend of an oil and casing thread is strongly dependent on operating torque of make-up ${ }^{[15]}$, AF- 01 can effectively decrease the galling of casing thread.

Results of full-scale make and break tests for knuckle-thread casing of P110S steel. The make-up torques of P110S are used the reference for P110. According to the GB/T 17745-1999 standard for P110 steel, the minimum torque, the maximum torque, and the optimal torque for the same P110 casing are $5790 \mathrm{~N} \cdot \mathrm{m}, 9650 \mathrm{~N} \cdot \mathrm{m}$, and $7720 \mathrm{~N} \cdot \mathrm{m}$, respectively. The $\mathrm{J}$ value and torques of the five groups for casings are shown in Table 3 .

TABLE.3 RESULTS OF THE MAKE-UP TEST

\begin{tabular}{cccccc}
\hline Coating type & $\mathrm{S} / \mathrm{mm}$ & $\mathrm{A} / \mathrm{mm}$ & $\mathrm{J} / \mathrm{mm}$ & $\mathrm{N}_{\max } /(\mathrm{N} \cdot \mathrm{m})$ & Situation of galling \\
\hline Reference & 10 & 16.90 & - & - & Serious galling \\
AF-01-1 & 10 & 18.36 & 11.0 & 7552 & No galling \\
AF-01-2 & 10 & 17.20 & 12.6 & 7781 & No galling \\
AF-01-3 & 10 & 16.90 & 13.5 & 7431 & No galling \\
AF-01-4 & 10 & 18.20 & 11.6 & 7399 & No galling \\
\hline
\end{tabular}

The serious galling on the reference (phosphate) casing is shown in Fig.7.

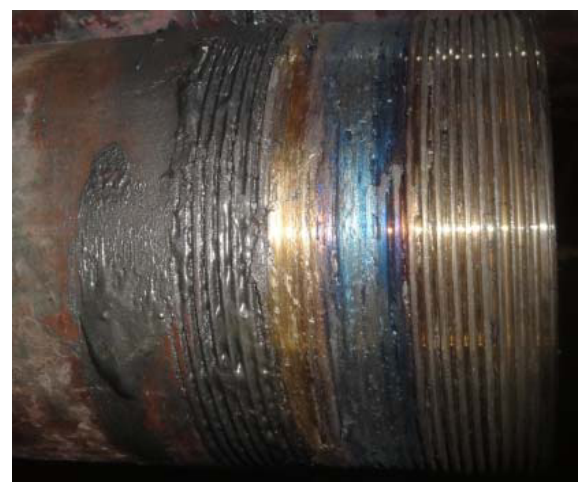

Fig.7 The surface morphology of galling on the reference casing

Fig. 8 shows the appearance of the casing thread surface of the four AF-01 casings after break-out. The thread surfaces were perfect and no galling occurred. 


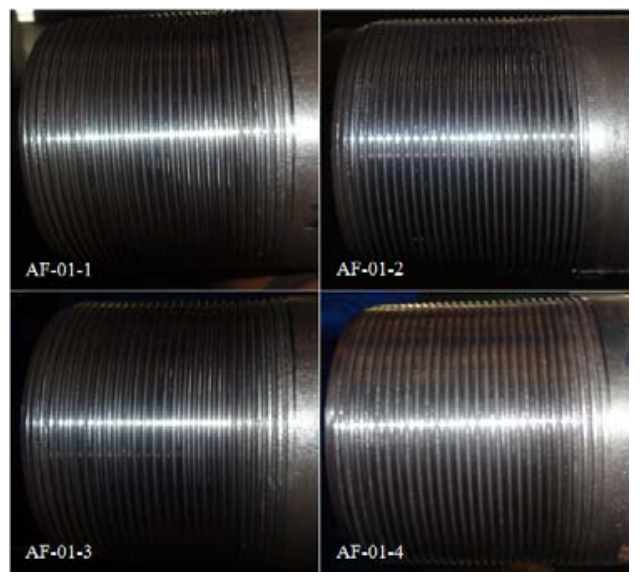

Fig. 8 The surface morphologies of the four AF-01 casings

Fig. 7 and Fig. 8 show that the reference casing underwent significant galling in the process of make and break, but the AF-01 casings were perfect and no galling occurred, and that the $\mathrm{J}$ values and controlled torque meet the standard requirements. Therefore, it can be concluded that AF-01 can replace the copperized coupling of P110S to prevent the galling of a phosphate-treated P110S casing. AF-01 can not only prevent the galling of the P110S casing, but can also reduce the cost and protect the environment greatly.

\section{Conclusions}

(1) A new type of anti-galling coating, AF-01, was used on the phosphate layer and was shown to significantly reduce the friction coefficient, as determined by tribo tests.

(2) SEM analysis of the grinding cracks show that the friction of the AF-01 coating occurs inside the coating, thereby protecting the phosphate layer from wearing out. The nano-particles in the AF-01 coating can form a firmly attached anti-friction nano-size copper layer together with the phosphate layer on the sample surface, which presents an effect similar to having nano balls and a copper layer, resulting in a perfect combination of anti-friction and lubrication effects.

(3) The full-scale make and break tests for knuckle-thread casing of P110 steel show that the integrated effect of AF-01 was the best among the four samples tested, and can significantly reduce the make-up torque of casing and thus prevent galling of the thread. A heterogeneous copper layer is formed after curing of AF-01, and it can block direct contact of the steel, reducing the make-up torque coupling by $20 \%$ more than that of the phosphate casings.

(4) The full-scale make and break tests for knuckle-thread casing of P110S steel show that AF-01 can prevent the galling of the P110S phosphate coupling perfectly, and consequently can replace the normal copperized coupling in sulfur-resistant P110S casing. Moreover, the use of AF-01 can achieve improved quality of tubing connection, with energy conservation and reduced emissions and cost. 


\section{References}

1. Ma Liubao,zhu Jing,Lai Xingtao.Analysis of Causes for Oil Tubing/Casing Galling Failure and Development of Anti-galling Technique [J].Steel Pipe,2011,40(3):27-30.

2. Zhang Desong.Performance study on the anti-galling of tubing thread [J].China Petroleum Machinery,2005,33(5):23-25.

3. ISO 13679, Petroleum and natural gas industries-Testing procedures for Casing and Tubing Connections [S].

4. Song Zhi, Feng Yaorong.Technology and application of oil well pipe and tube column [M].Beijing:Petroleum Industry,2007:37-38.

5. Zhang Yi,Li Xin, Chen Jianchu.Research On the Influencing Elements of Oil Casing Sticky Thread Principle and Classification Points [J].Welding Pipe,2002,25(2):13-22,25.

6. Dong Changle,Wang Min,Hao Ning.Study on Effect of Make-up Torque on Casing Galling [J].Liaoning Chemical Industry,2010,39(11):1191-1193.

7. Du Chuanjun.Influence of Coupling Copperizing on Anti-galling Performance of Tubing Threads [J].Baosteel Technology,2001,(3):28-30.

8. Meng Zhao,Yang Yun,Zhao Shilong,et al.Application of Composite Nano-copper/PTFE Friction Reducing Coating in Oil Country Tubular Goods [J].Lubrication Engineering,2014,39(7):93-97.

9. Meng Zhao,WangLi.A Method Industrial Production of Copper Nano-particles.China Patent:102407344A [P].2012-04-11.

10. Meng Zhao,Yang Yun.Method Industrial Production and Application for A Composite Nanoparticulate Anti-galling Coating. China Patent:102977714A [P].2013-03-20.

11. Zhao Meng, Yi Li, Yun Yang,et al. Effect of a nanoparticulate anti-friction coating on galling resistance of threaded oil-casing Couplings [J].Journal of Petroleum Science and Engineering, in press.

12. Zhai Lanlan,Ling Guoping.The influence of nanoparticles on the adhesion strength between epoxy resin and steel substrate [J]. China Adhesives,2007,16(1):19-22.

13. Zhou J F, Yang J F,Zhang Z J,et al. Study on Structure and Tribological Properties of Surface-Modified $\mathrm{Cu}$ Nanoparticles [J].Materials Research Bulletin,1999,34(9):1 361-1 367.

14. Wang Jian,Jiang Li,Qi Qinhua,et al.Study on the Properties of Lubrication 0il with Copper Nanoparticals as Additive [J].Lubrication Engineering,2009,34(3):66-69.

15. Ji Kangling. The experiment studies on the factors affecting the round thread casing and tubing gluing [J].Technology Supervision in Petroleum Industry,2005,(4):14-17. 